\title{
Similar eficacia de las tiazidas y otras drogas como tratamiento de primera línea de la Hipertensión Arterial
}

Major Outcomes in high risk hypertensive patients randomized to Angiotensin-Converting Enzyme Inhibitor or Calcium Channel Blocker vs Diuretic:the Antihypertensive and Lipid Lowering Heart Attack Trial (ALLHAT), JAMA 2002;288:2981-2997

\section{Objetivo}

Determinar si la incidencia de Enfermedad Coronaria (EC) fatal o infarto (IAM) no fatal es menor en pacientes hipertensos de alto riesgo tratados con nuevas drogas como inhibidores de la enzima convertidora (IECA) o Bloqueantes cálcicos (BC) comparado con diuréticos.

\section{Lugar}

Estudio Multicéntrico realizado en EE.UU., Canadá y Puerto Rico

\section{Pacientes}

Se aleatorizaron 42.418 pacientes hipertensos mayores de 55 años. En aquellos sin tratamiento debían tener una TA mayor a 140/90 y menor 180/110 y en aquellos tratados menos de 160/100. Debían cumplir además con la presencia de por lo menos uno de los siguientes criterios:infarto ó accidente cerebrovascular (ACV) de más de seis meses, otra enfermedad ateroesclerótica, procedimientos de revascularización, diabetes, tabaquismo, $\mathrm{HDL}<$ 35, ó presencia de hipertrofia ventricular izquierda.

\section{Intervención}

Los pacientes fueron aleatorizados a recibir clortalidona 12,5 a $25 \mathrm{mg}$, amlodipina 2,5 a 10mg., o lisinopril 10 a $40 \mathrm{mg}$.

\section{Medición de los resultados principales}

El resultado primario era la combinación de EC fatal o IAM no fatal. Resultados secundarios eran mortalidad total, ACV, EC combinada (EC fatal, IAM no fatal, angina sin internación, procedimientos de revascularización), Cardiovascular combinada (EC fatal, IAM no fatal, stroke, angina sín internación, insuficiencia cardíaca y enfermedad vascular periférica).

\section{Resultados Principales}

La media de seguimiento fue de 4,9 años. La distribución inicial en los distintos grupos fue similar.La edad media fue de 67 años, la media de presión arterial de comienzo era 146/84, $47 \%$ eran mujeres, $35 \%$ de raza negra, y $36 \%$ diabéticos.

Tabla. Resultados primarios y secundarios

\begin{tabular}{|c|c|c|c|c|c|}
\hline & $\begin{array}{c}\text { Clortalidona } \\
n=15255\end{array}$ & $\begin{array}{c}\text { Amlodipina } \\
\mathrm{n}=9048\end{array}$ & $\begin{array}{c}\mathbf{R R} \\
(\text { IC } 95 \%)^{*}\end{array}$ & $\begin{array}{c}\text { Lisinopril } \\
\mathrm{n}=9054\end{array}$ & $\begin{array}{c}\text { RR } \\
(\text { IC 95\% })^{\star *}\end{array}$ \\
\hline $\begin{array}{l}\text { EC fatal ol } \\
\text { IAM no fatal }\end{array}$ & 1362 & 798 & $\begin{array}{c}0,98 \\
(0,9-1,02)\end{array}$ & 796 & $\begin{array}{c}0,99 \\
(0,9-1,08)\end{array}$ \\
\hline Mortalidad Total & 2203 & 1256 & $\begin{array}{c}0,96 \\
(0,89-1,02)\end{array}$ & 1314 & $\begin{array}{c}1 \\
(0,94-1,08)\end{array}$ \\
\hline CV combinada & 3941 & 2432 & $\begin{array}{c}1,04 \\
(0,99-1,09)\end{array}$ & 2514 & $\begin{array}{c}1,10 \\
(1,05-1,16)\end{array}$ \\
\hline $\begin{array}{l}\text { Insuficiencia } \\
\text { Cardíaca }\end{array}$ & 870 & 706 & $\begin{array}{c}1,38 \\
(1,25-1,52)\end{array}$ & 612 & $\begin{array}{c}1,19 \\
(1,07-1,39)\end{array}$ \\
\hline
\end{tabular}

*Amlodipina en comparación con Clortalidona

**Lisinopril en comparación con Clortalidona

Porcentaje (\%) de meta de TA $<140 / 90$ alcanzada y diferencias de presión arterial sistólica (PAS) al final del seguimiento

\begin{tabular}{l|c|c|c|c|c} 
& $\begin{array}{c}\text { Clortalidona } \\
\mathbf{n = 1 5 2 5 5}\end{array}$ & $\begin{array}{c}\text { Amlodipina } \\
\mathbf{n}=\mathbf{9 0 4 8}\end{array}$ & Valor de $\mathbf{p}$ & $\begin{array}{c}\text { Lisinopril } \\
\mathbf{N}=9054\end{array}$ & Valor de $\mathbf{P}$ \\
\hline \% de TA & 3615 & 2118 & $\mathrm{p}=0,09$ & 1813 & $\mathrm{p}<0,001$ \\
$<140 / 90$ & $(68,2 \%)$ & $66,3 \%)$ & & $(61,2 \%)$ & \\
\hline Media de PAS & 133.9 & 134.7 & $\mathrm{p}<0,03$ & 135,9 & $\mathrm{p}<0.01$ \\
& $(15.2)$ & $(14.9)$ & & $(17.9)$ & \\
\hline
\end{tabular}

\section{Conclusión}

Los diuréticos tiazídicos son superiors en prevenir una o más formas de enfermedad cardiovascular y son más baratos. Deben preferirse como primer paso en la terapéutica antihipertensiva.

\section{Comentario}

Los grandes estudios sobre temas tan prevalentes como la hipertensión arterial suelen tener un fuerte impacto en las conductas médicas y en la opinión pública pero cuando los resultados de los mismos son divergentes puede haber además una gran confusión y desconfianza en la ciencia. ${ }^{1}$ El estudio ALLHAT concluyó que los diuréticos controlan mejor la tensión arterial (TA) y otorgan mejores resultados que los IECA mientras que el estudio ANBP ${ }^{2}$ mostró resultados opuestos con similar control de la TA. Es menester en primer lugar intentar explicar el porqué de las diferencias y en segundo tratar de definir una postura razonable para la aplicación práctica.

Podría postularse que las diferentes drogas comparadas en cada estudio podrían explicar las discordancias. Aunque no hay, y probablemente no habrá, estudios cabeza a cabeza que comparen entre sí a las tiazidas ni a los IECA, todas las evidencias hacen suponer un efecto de clase $^{2}$ para ambos grupos de drogas haciendo poco probable esta hipótesis. Lo que si complejiza las comparaciones entre ensayos, y podría generar diferencias, son las distintas drogas asociadas para alcanzar la meta de control de TA. EI ALLHAT comparó alfa bloqueantes, IECA, bloqueantes cálcicos y tiazidas por lo que las asociaciones posibles fueron poco comunes (simpaticolíticos en lugar de diuréticos o bloqueantes cálcicos). Esto pudo haber contribuido a que $7 \%$ menos pacientes del grupo IECA que del grupo diurético alcanzaran la meta de TA $<140 / 90$ y por ende a que tuvieran peores resultados especialmente en una población de alto riesgo como la del ALLHAT.Por el contrario en el $\mathrm{ANBP}^{2}$ y en la vasta mayoría de estudios comparativos de antihipertensivos logran similares controles de TA en las distintas ramas dada la posibilidad de titular dosis y asociar drogas. Otra posible fuente de disparidad es que 1/3 de la población del ALLHAT era de raza negra, de conocida peor respuesta a los IECA, en cambio en al $\mathrm{ANBP}^{2}$ el $95 \%$ eran blancos. También debe mencionarse las diferencias en la definición de los resultados que además eran combinados.De hecho ningún es- 


\section{Los inhibidores de la enzima de conversión fueron algo superiores a las tiazidas}

A comparison of Outcomes with Angiotensin Converting Enzyme Inhibitors and Diuretics for Hypertension in the Elderly. Wing L, Reid C, Ryan P, et al. N Engl J Med 2003;348:583-92

\section{Objetivo}

Comparar los resultados del tratamiento antihipertensivo entre sujetos ancianos tratados con Inhibidores de la Enzima Convertidora (IECA) con respecto a diuréticos tiazídicos.

\section{Diseño}

Ensayo clínico aleatorizado abierto con evaluación ciega de los resultados.

\section{Lugar}

1594 médicos de familia de Australia

\section{Pacientes}

Pacientes hipertensos mayores de 65 años, con una presión arterial sistólica (PAS) $>$ de $160 \mathrm{mmHg} 0>90 \mathrm{mmHg}$ de diastólica si la PAS era $>140 \mathrm{mmHg}$

\section{Intervención}

Se aleatorizaron 6.083 sujetos a recibir enalapril o hidroclorotiazida. La meta inicial era llegar a un disminución de $20 \mathrm{mmHg}$ por debajo de $160 \mathrm{mmHg}$ de PAS. Los médicos de familia eran los responsables del manejo de la presión, la asignación era una recomendación que podía ser cambiada.

\section{Medición de resultados principales}

El objetivo primario era la combinación de eventos cardiovasculares totales o muerte por cualquier causa. Los objetivos secundarios eran medición de primer evento vascular y muerte total, causas cardiovasculares específicas como infarto de miocardio, angina inestable, ACV, insuficiencia cardíaca, procedimientos de revascularización y otros vasculares.

\section{Resultados Principales}

Los pacientes fueron seguidos por una media de 4,1 años. Las características de ambos grupos fueron similares. Hubo $50 \%$ de mujeres, edad promedio de 72 años, presión inicial 168/91 mmHg., el $7 \%$ eran diabéticos. La disminución de la presión fue similar en ambos grupos siendo al final del estudio de $26 / 12 \mathrm{mmHg}$.

\section{Resultados sobre eventos cardiovasculares}

\begin{tabular}{l|c|c|c} 
& Enalapril $(\mathbf{n}=\mathbf{3 0 4 4})$ & Diuréticos( $\mathbf{n = 3 0 3 9 )}$ & RR (IC 95\%) \\
$\begin{array}{l}\text { Eventos CV totales } \\
\text { y muerte total }\end{array}$ & 695 & 736 & $0,89(0,79-1,00)$ \\
\hline $\begin{array}{l}\text { Primer evento CV } \\
\text { y muerte total }\end{array}$ & 490 & 529 & $0,89(0,79-1,01)$ \\
\hline Muerte total & 195 & 210 & $0,90(0,75-1,09)$ \\
\hline Primer evento CV & 394 & 429 & $0,88(0,77-1,01)$ \\
\hline Insuficiencia cardíaca & 69 & 78 & $0,85(0,62-1,18)$ \\
\hline
\end{tabular}

Al realizar el análisis estratificado por sexo, se observó que el beneficio de los IECA es mayor en el sexo masculino RR 0,83 IC $95 \%(0,71-0,97)$ para el resultado primario de eventos CV totales y muerte total así como primer evento CV y muerte total.No hubo diferencias en las mujeres.

\section{Conclusión}

El inicio del tratamiento antihipertensivo con IECA en ancianos y particularmente en hombres con respecto a los diuréticos parece llegar a mejores resultados a pesar de tener iguales reducciones en la presión arterial. tudio mostró diferencias estadísticamente significativas en los resultados 1 arios para los que fueron específicamente diseñados pero sí cuando se empiezan a incorporar combinaciones de distintos eventos.

Conclusiones del comentador: si bien tanto diuréticos como IECA son altamente efectivos frente al placebo, hasta el momento por estos estudios no hay evidencias claras de superioridad de una droga;con lo cual por evidencia acumulada y costos confirma a los diuréticos como tratamiento de primera elección para la HTA especialmente en pacientes sin comorbilidades. En pacientes con diabetes, insuficiencia cardíaca o historia de infarto de miocardio sería razonable iniciar con IECA especialmente si son añosos. No debemos perder de vista que frecuentemente se necesitan asociaciones lo cual es perfectamente razonable con estas dos grupos de antihiper tensivos.Por otro lado se refuerza el concepto del $\mathrm{HOT}^{3}$ de mayores los beneficios cuanto mejor sea el control de la TA.Considerando que aproximadamente de todos los hipertensos sólo el $50 \%$ lo sabe, que el $50 \%$ éstos se trata y sólo un $25 \%$ en forma apropiada ${ }^{4}$ nuestros esfuerzos deberían estar dirigidos a diagnosticar hipertensos y a controlar apropiadamente la TA independientemente de la droga elegida.

\section{Dr. Agustín Ciapponi [ Unidad de Medicina Familiar y Preventiva. Hospital Italiano de Buenos Aires ]}

\section{Referencias}

1. Frohlich ED Treating hypertension - what are we to believe?N Engl J Med. 2003;348(7):639-41

2. Soares I, Carneiro AV. Drug class effects: definitions and practical applications. Rev Port Cardiol.2002;21(9):1031-42. Review.

3. Hansson L, Zanchetti A, Carruthers S, et al.Effects of intensive blood-pressure lowering and low-dose aspirin in patients with hipertension:principal results of the Hipertension Optimal Treatment (HOT) randomised trial Lancet 1998; 351:1755-1762.

4.Burt VL, Cutler JA, Higgins M, Horan MJ, Labarthe D, Whelton P, Brown C, Roccella EJ.Trends in the prevalence, awareness, treatment, and control of hypertension in the adult US population. Data from the health examination surveys, 1960 to 1991. Hypertension. 1995 山l:26(1):60-9. 